\title{
O Design de Adornos Corporais em um Cenário de Mudanças Tecnológicas
}

The Accessory Design in a Technological Changing Scenario

TAVARES, Thayane; Mestranda; Pontifícia Universidade Católica do Rio de Janeiro tnstavares@gmail.com

MAGALHÃES, Claudio; Doutor; Pontifícia Universidade Católica do Rio de Janeiro

claudio-design@puc-rio.br

\section{Resumo}

Considerando a indústria de joias e bijuterias, este artigo visa apontar os aspectos presentes no ambiente de atuação do designer de adornos corporais e possíveis impactos no campo resultantes da adoção de tecnologias de modelagem paramétrica, digitalização tridimensional e impressão aditiva em metal. Mostra também como estas tecnologias são utilizadas no momento e indica outras formas de aplicação que podem beneficiar o setor.

Palavras Chave: design de joias; design paramétrico; fabricação digital.

\section{Abstract}

Taking in consideration the jewelry and costume jewelry industry, this article aims to present the aspects involved in the accessory designer's working field and the possible impacts caused by the adoption of parametric modeling, 3D scanning and additive manufacturing of metal. The article also shows how these technologies are applied at the present and indicates other possible applications that can benefit the field.

Keywords: jewelry design; parametric design; digital fabrication. 


\section{Introdução}

Nos últimos anos, a indústria de joias e bijuterias passou por mudanças significativas. Segundo Benz (2009), a modelagem 3D e a prototipagem rápida trouxeram melhorias na qualidade dos produtos, introduziram mudanças no processo de fabricação e abriram novas possibilidades no campo do design.

De acordo com Espinoza (2013), para que o setor joalheiro sobreviva frente à competitividade do mercado, ele deve profissionalizar suas atividades, incluindo acréscimo constante de tecnologia na produção. Esse fato é evidenciado por Villamizar e Rodríguez (2015), que afirmam a necessidade de modernizar os processos tradicionais de desenho e fabricação com o apoio de ferramentas digitais.

Este artigo expõe as novas tecnologias de modelagem paramétrica e fabricação digital que podem contribuir para o ramo de adornos corporais e discorre sobre os aspectos relacionados ao seu uso no ambiente de atuação do designer.

\section{Conceito de adorno corporal}

A portaria $n^{\circ} 43$ do Inmetro, de 22 de janeiro de 2016, define bijuteria e joia como:

(...) qualquer adorno, masculino ou feminino, de metal ou não, que o seu uso propicie o contato deste ou parte deste com o corpo humano, tais como: I -contas metálicas e outros componentes metálicos para fabricação de peças de Joalheria; II - artigos de Joalheria e de Bijuteria, metálicos, incluindo: a) acessórios para o cabelo; b) pulseiras, colares e anéis; c) piercings; d) adornos para os pulsos, incluindo relógios e outros; e) abotoaduras; f) brincos (INMETRO, 2016).

O conceito de joia e bijuteria do Inmetro pode ser aplicado ao entendimento do que é adorno corporal: tudo aquilo que é utilizado junto ao corpo, exceto itens de vestuário, fabricado em materiais variados.

No Cadastro Nacional de Atividades Econômicas (CNAE) do IBGE, as indústrias de joalheria e bijuteria estão no mesmo grupo, havendo diferenciação somente em classe:

Quadro 1 - Cadastro Nacional de Atividades Econômicas

\begin{tabular}{lll}
\hline Seção & C & Indústrias de Transformação \\
\hline Divisão & 32 & Fabricação de Produtos Diversos \\
\hline Grupo & 321 & Fabricação de Artigos de Joalheria, Bijuterias e Semelhantes \\
\hline
\end{tabular}

Fonte: adaptado de cnae.ibge.gov.br (2018)

Já o setor industrial, de uma forma geral, diferencia joia e bijuteria através do material empregado para a fabricação. A bijuteria utiliza metais não-nobres e/ou outras matérias-primas, ao contrário da joia. Também há diferenciação entre bijuteria e semijoia, sendo a última um tipo de bijuteria que leva banhos de metais nobres, garantindo aspecto de joia. 
Segundo Franco (2017), na nossa sociedade, a palavra joia está ligada a um imaginário construído através dos séculos e que remete à confecção em metais nobres e pedras preciosas. A origem da joalheria ocidental está principalmente na cravação de pedras (DEN BESTEN, 2011 apud FRANCO, 2017), e esse tipo de produção, conhecida como Joalheria Clássica, é mantida ainda nos dias de hoje.

Atualmente, há a Joalheria Contemporânea, que permite o uso de materiais inusitados para o ramo joalheiro. Nascida na década de 1960, está alinhada com a prática reflexiva da Arte Contemporânea.

Sobre a Joalheria Contemporânea, Franco (2017) afirma que:

No total da produção do que hoje se autodenomina joalheria, podemos identificar uma parte que se preocupa e está comprometida com a discussão de assuntos do seu tempo e a geração de ideias. A esta produção, denominamos de Joalheria Contemporânea e ela busca atender uma demanda social de novas possibilidades de ressignificações de corpos de forma temporária. (...) A mensagem se completa no uso e nos ajuda a refletir assuntos de nosso tempo relacionados ao corpo (FRANCO, 2017, p. 87).

Para fins deste artigo, será adotada a expressão "adorno corporal" para referir-se ao grupo de objetos cujo fim é adornar o corpo, sejam eles joias clássicas, joias contemporâneas, bijuterias ou outros tipos de acessórios. A opção por essa forma de classificação deve-se à similaridade do processo produtivo e materiais, facilitando assim a análise, e também por não haver intenção neste momento de entrar em detalhes subjetivos sobre o que deve ser considerado como joia.

\section{Relevância econômica}

O setor de joias e bijuterias insere-se na chamada economia criativa, definida pela Equipe Senai Moda Design do Sistema Firjan como:

(...) o conjunto de atividades econômicas que dependem do conteúdo simbólico - nele incluído a criatividade como fator mais expressivo para a produção de bens e serviços, guardando estreita relação com aspectos econômicos, culturais e sociais que interagem com a tecnologia e propriedade (MAPEAMENTO DA INDÚSTRIA CRIATIVA NO BRASIL, 2014, p. 25).

Os bens e serviços dessa economia são produzidos pelas indústrias criativas. Em 2011, essas indústrias geraram um PIB de R\$110 bilhões, ou seja, 2,7\% de tudo o que é produzido no país.

Segundo a Firjan, são pertencentes à indústria criativa as atividades que tem sua origem na criatividade, na perícia e no talento individual e que possuem um potencial para a criação de riqueza e empregos através da geração da exploração de propriedade intelectual (MAPEAMENTO DA INDÚSTRIA CRIATIVA NO BRASIL, 2014, p. 25).

Ainda de acordo com a publicação, o mercado de joias passa por um momento de expansão e maior profissionalização. O design inovador norteia a evolução do setor, agregando valor além do financeiro. A forma encontrada de garantir o crescimento e destacar-se no mercado é investir em inovação, desenvolvimento do produto e conhecimento técnico. 


\section{Aspectos Tecnológicos de Criação e Produção}

Segundo Batista (2013), a partir dos anos de 1980, os softwares CAD (Computer Aided Design) têm sido a ferramenta mais utilizada nas representações gráficas, pois possibilitam maior precisão, rapidez e facilidade de comunicação entre os diversos setores produtivos. Viaro et al. (2014) também apontam que os protótipos digitais podem auxiliar na comunicação eficaz entre a equipe de desenvolvimento e os stakeholders (i.e., todos os interessados e envolvidos no processo de projeto).

A produção completa da joia pelo ourives e a modelagem manual em cera utilizadas pela indústria de joias e bijuterias vêm sendo substituídas pela modelagem 3D digital e pela prototipagem rápida.

\subsection{Modelagem Paramétrica}

A modelagem digital paramétrica é uma forma de construção de modelos virtuais diferente do que é entendido como modelagem digital tradicional. Possui os mesmos benefícios que a tradicional, como visualização sob vários ângulos, precisão, espelhamento e outros, com uma diferença fundamental: a possibilidade de alterações com maior eficiência.

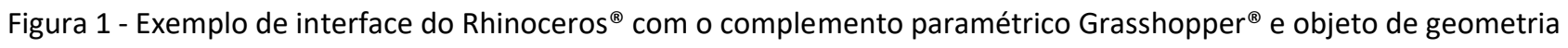
complexa modelado

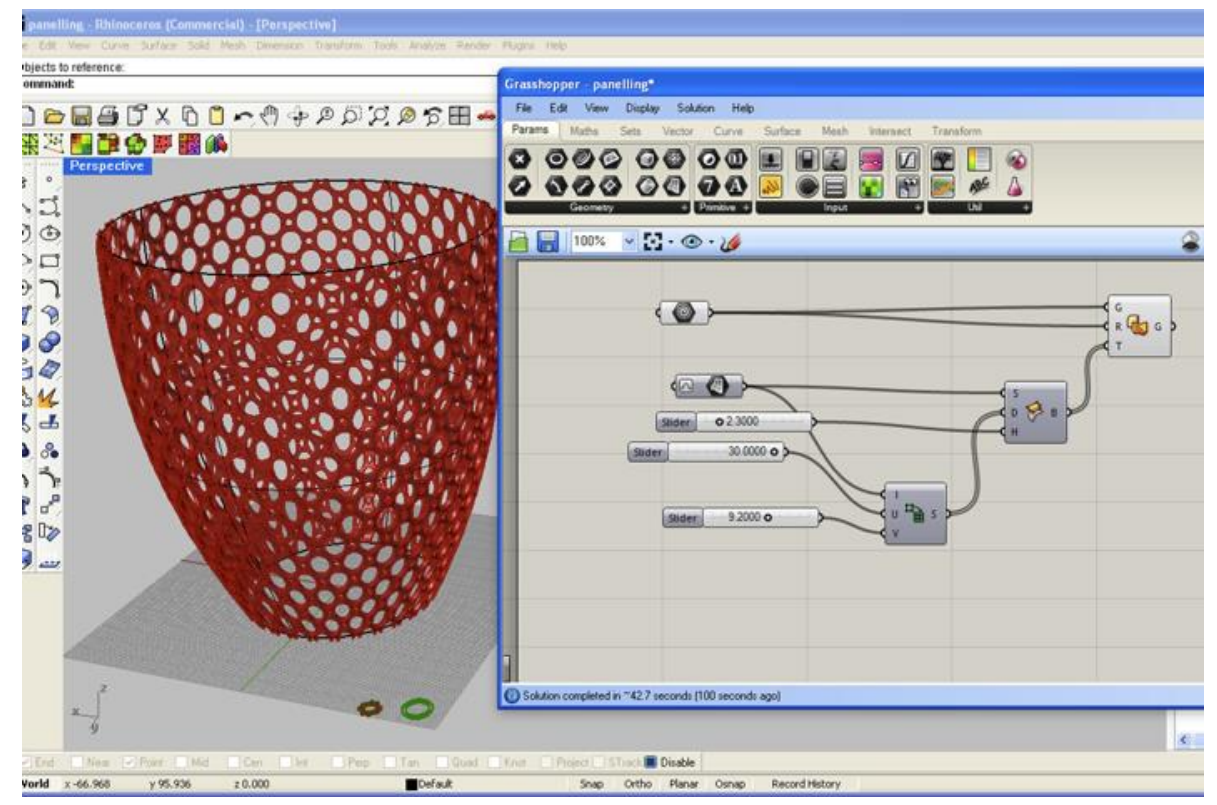

Fonte: digitalphysicalities.com (2018)

Villamizar e Rodríguez (2015) apontam a modelagem paramétrica como um método de criação de geometrias complexas. Essa forma de modelagem permite que, ao alterar um parâmetro, o modelo 3D seja readequado em cadeia, poupando tempo e trabalho para realizar alterações. Ao contrário da modelagem tradicional, em que cada modelo precisaria ser criado basicamente do início (Gulati et al., 2010). 
Design Paramétrico, atualmente, refere-se genericamente à utilização de software de modelagem paramétrica. Softwares paramétricos admitem ligar parâmetros numéricos e geométricos, permitindo assim ajustes incrementais de uma peça que, em seguida, afeta todo modelo em cadeia. A diferença do design paramétrico para o processo tradicional de projeto é que no design paramétrico as partes do projeto são inter-relacionadas e mudam juntas, de forma coordenada. Essa conexão facilita mudanças, relações, adições e reparos no projeto, reduzindo retrabalho e facilitando possibilidades (LEACH, 2014 apud VOLTOLINI, 2016, p. 34).

A utilização de parâmetros que norteiam as alterações em cadeia permite a modelagem de estruturas geométricas complexas e com padrões de repetição, como polígonos de Voronoi (figura 1), que seriam extremamente trabalhosos para desenvolver através da modelagem tradicional.

Atualmente, há no mercado softwares e plug-ins paramétricos disponíveis especificamente para a modelagem de acessórios, como o 3Design ${ }^{\circledR}$, RhinoGold $^{\circledR}$, ByzantineCAD $^{\circledR}$ e outros. É possível também utilizar modeladores de uso geral, como o Rhinoceros ${ }^{\circledR}$ em conjunto com o complemento paramétrico Grasshopper ${ }^{\circledR}$. A vantagem do programa específico para o segmento de adornos está na disponibilidade de ferramentas voltadas à atividade, como biblioteca de gemas e materiais, cravação automática, grifas e diâmetro da aneleira (figura 2).

Figura 2 - Exemplo de modelagem no software 3Design ${ }^{\circledR}$, exclusivo para a fabricação de joias, bijuterias e relógios

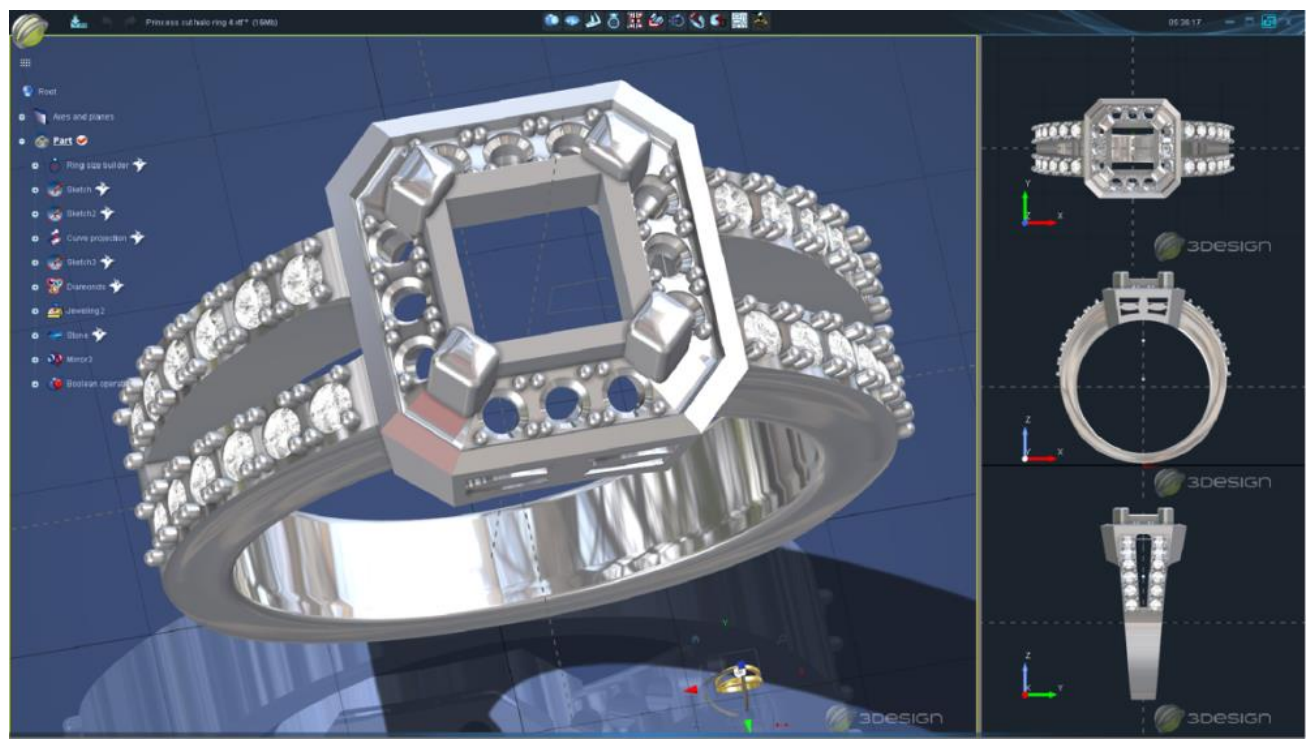

Fonte: 3design.com (2018)

É notável que os programas são prioritariamente voltados para o design de joias. Contudo, a modelagem paramétrica e as técnicas de fabricação digital empregadas no setor joalheiro podem também oferecer oportunidades de desenvolvimento a outros setores produtivos, como o de calçados, bijuterias, moda e decoração, como apontado por Villamizar e Rodríguez (2015). O desenvolvimento de bijuterias e de relógios é bastante similar ao da joia em muitos aspectos de design e fabricação. 
As gemas de cor utilizadas na joalheria normalmente não são calibradas, sendo necessário adequar cada modelo de produto para a respectiva pedra. A parametrização permite que ao modificar as medidas e a forma da gema, o modelo virtual mude em cadeia, pulando etapas na modelagem e trazendo maior velocidade ao processo. A árvore de comandos também pode proporcionar o processo de engenharia reversa: ao desmontar o modelo virtual, é possível compreender como foi feita a construção e assim aprender a técnica empregada.

Já o setor de bijuterias é marcado pela alta informalidade e terceirização de serviços, que propiciam o surgimento de imitações das peças (GIULIO, 2007). O desenvolvimento de novos produtos é a forma encontrada para enfrentar o problema da cópia. Nesse cenário, a modelagem paramétrica traz como benefício a possibilidade de desenvolver variações ou novos modelos com a agilidade necessária ao setor e maior confiabilidade na qualidade dos protótipos e peças piloto, já que é possível utilizar como base para alterações as peças já disponíveis no catálogo de produtos da empresa.

O principal polo produtivo de bijuterias está localizado na cidade de Limeira, em São Paulo, e é formado em sua grande maioria por micro e pequenas empresas familiares (GIULIO, 2007). Como apontado pelo Mapeamento da Indústria Criativa no Brasil (FIRJAN, 2014), a concorrência com países asiáticos é, além de crescente, um motivo de preocupação para o ramo de bijuterias, enquanto o ramo joalheiro está mais preparado para enfrentar essa ameaça devido à maior qualidade de seus produtos e ao investimento em design diferenciado.

Além disso, para manter o preço competitivo os fornecedores do setor de bijuterias precisam também trabalhar com grandes quantidades, o que resulta em pouca variedade. Vale destacar que o uso da modelagem paramétrica aliada às novas tecnologias de fabricação permite também a produção em massa de produtos personalizados (ORCIUOLI, 2013 apud VIARO et al., 2014). As novas tecnologias poderiam trazer uma oportunidade para o setor investir em design diferenciado e customização a custos reduzidos, ampliando a capacidade de atender aos desejos e demandas dos clientes.

Por meio da modelagem paramétrica e prototipagem rápida das peças, obtêm-se acessórios de alta complexidade formal, alta precisão e excelente qualidade (Villamizar e Rodríguez, 2015). Mas os benefícios vão além da forma e economia de tempo, já que essa tecnologia facilita o treinamento e capacitação de mão-de-obra através da possibilidade de engenharia reversa. Em um setor marcado pela alta informalidade, a troca de conhecimento produtivo é crucial.

Por fim, é importante destacar que a modelagem paramétrica traz possibilidades de inovação no design de adornos corporais que vão além da fabricação. Mineiro (2016) aponta que inicialmente, no processo de design, o computador foi utilizado para trazer maior precisão e eficiência. Explorar novas possibilidades não era uma prioridade, fato que não é mais condizente com a atualidade. Mineiro (2016) exemplifica essa conjuntura com a criação flexível de geometrias complexas, apoiadas pelos sistemas paramétricos.

Traçando um paralelo com o ramo de adornos corporais, nota-se que as tecnologias de design computadorizado são empregadas para executar as mesmas formas de joias produzidas em banca de 
ourives, portanto não houve inovação relativa à forma. A modelagem paramétrica, ao permitir explorar geometrias complexas que seriam extremamente trabalhosas caso projetadas através da modelagem tradicional, traz uma verdadeira possibilidade de inovação ao design de adornos corporais.

\subsection{Digitalização Tridimensional}

Uma tecnologia que pode ser empregada junto à modelagem paramétrica a fim de otimizar a produção de adornos, mas ainda pouco difundida na indústria, é a digitalização tridimensional. Essa tecnologia serve para captar imagens 3D de um objeto real com auxílio de ferramentas computacionais que permitem obter com grande precisão de detalhes da superfície, texturas e até objetos inteiros (SILVA, 2006 apud SOUZA, 2010). A digitalização tridimensional pode ser entendida como uma forma de transformar um objeto físico em um modelo virtual.

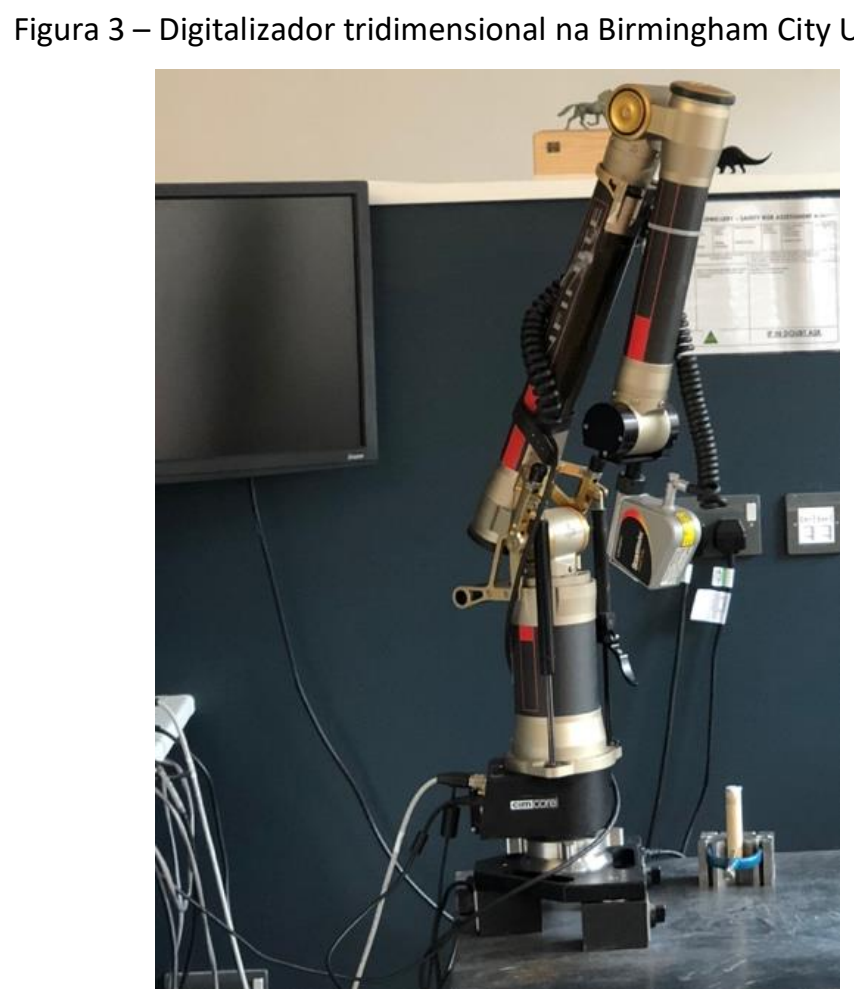

Fonte: a autora

Aplicada à joalheria, a digitalização tridimensional permite maior aproveitamento volumétrico da pedra bruta a ser lapidada, já que através do modelo virtual será possível testar a melhor lapidação para o caso, e também será possível a criação de um banco de dados com lotes de gemas digitalizadas, o que resultaria em maior agilidade na produção pois gemas similares poderiam ser utilizadas para produzir joias de um mesmo modelo (SOUZA, 2010). Além disso, permitiria a construção de uma "boneca" (nome dado ao modelo volumétrico da gema a ser utilizada no produto final) com medidas precisas, evitando que a pedra verdadeira seja manuseada durante o processo de 
desenvolvimento do produto. A boneca poderia ser impressa em 3D, sendo entregue aos setores fabris que produzirão a joia. A gema seria então manuseada somente no momento da cravação. Isso garante maior segurança, especialmente no caso de pedras frágeis ou de alto valor comercial.

Villamizar e Rodríguez (2015) apontam também o escaneamento 3D como uma técnica de engenharia reversa, que pode ser unida à parametrização e prototipagem rápida para produzir em série e com excelente qualidade os modelos de joias feitas à mão. O mesmo processo pode ser executado na produção dos demais produtos do ramo de adornos corporais, como bijuterias, relógios etc.

A aplicação da digitalização tridimensional possibilita também criar uma biblioteca de modelos similares que, unidos à parametrização, permitiria o desenvolvimento de produtos novos com rapidez e precisão.

Também é importante citar que, devido ao emprego de técnicas manuais de produção no setor de adornos corporais, como modelagem em cera ou soldagem, muitos componentes disponíveis no catálogo de produtos das empresas existem somente como um modelo físico (matriz). Essa tecnologia permitiria a criação de um catálogo virtual de produtos, facilitando a catalogação por parte dos produtores, com código, medidas, volume, material e outras informações pertinentes ao processo produtivo. Também garantiria segurança contra a destruição ou perda da matriz, pois o modelo 3D guarda todas as informações técnicas de construção da peça. Por fim, o catálogo virtual também poderia ser apresentado aos clientes como portfólio, auxiliando na tomada de decisão. Batista (2013) sustenta essa aplicabilidade ao afirmar que a visualização 3D permite observar a peça sob vários ângulos, reduzir ou ampliar para perceber os detalhes, além de tornar possível simular a realidade para os clientes visualizarem a peça como se ela já estivesse pronta.

\subsection{Impressão 3D aditiva em metal}

A aplicação da modelagem paramétrica em conjunto com a digitalização tridimensional pode trazer diversos avanços ao setor de adornos corporais. Mas ambas são tecnologias para criação de modelos virtuais, sendo necessária a materialização dessas ideias através de outras técnicas, como a prototipagem rápida. Para isso, já está disponível e é amplamente utilizada a impressão 3D aditiva ou subtrativa. Para Neto et al. (2015), por fabricação aditiva entende-se a fabricação de um determinado modelo tridimensional, gerado por software CAD 3D, através de sobreposição sucessiva de camadas de material. Já a técnica subtrativa, segundo Batista (2013), promove o desbaste de blocos de diferentes materiais, sendo as máquinas mais comuns as fresadoras CNC (Controle Numérico Computadorizado).

$\mathrm{Na}$ indústria de joias, a fabricação por impressão aditiva e subtrativa é utilizada para a produção do modelo em resina ou cera, que será utilizado para dar origem ao produto final após fundição e trabalho em banca de ourives. Já na indústria de bijuterias, o produto fabricado por essas tecnologias pode ser tanto um modelo quanto um produto finalizado. O processo de usinagem, em que o metal é removido por uma fresa CNC de acordo com o modelo virtual fornecido, é bastante utilizado. 
Figura 4 - Exemplo de ponteira em latão para bijuterias feita por usinagem com fresa CNC

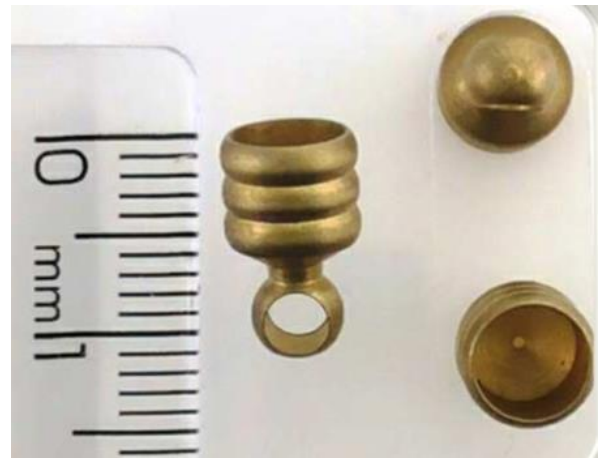

Fonte: catalogo.usineses.com.br

Contudo, a impressão 3D aditiva (ou fabricação aditiva) em metal ainda não é uma realidade nas indústrias do ramo. Segundo Hilkene (2017), o segmento que cresce de forma mais acelerada no ramo da impressão aditiva é a impressão em metal. De acordo com Neto et al. (2015), o processo de maior implementação industrial é o de fusão de camada de pó, onde o metal encontra-se na forma de pó e é depositado em camadas, unidas através da energia proveniente de um laser ou de um feixe de elétrons ou de um jato de liga em estado líquido.

Apesar das dificuldades relacionadas à qualidade superficial das peças e propriedades mecânicas, as técnicas de fabricação aditiva com metais estão evoluindo de forma contínua. A grande vantagem é que possibilitam a produção de peças com design e tempo de fabricação impossíveis de obter com processos convencionais (NETO et al., 2015). No mercado já estão disponíveis impressoras voltadas para a fabricação de joias, bijuterias e relógios. Pode-se utilizar cargas de metais preciosos, como ouro $18 \mathrm{k}$ ou $14 \mathrm{k}$ nas cores amarelo, vermelho e branco, prata, platina e até mesmo latão.

Figura 5 - Exemplo de esferas ocas com superfície complexa feitas por impressão em metal

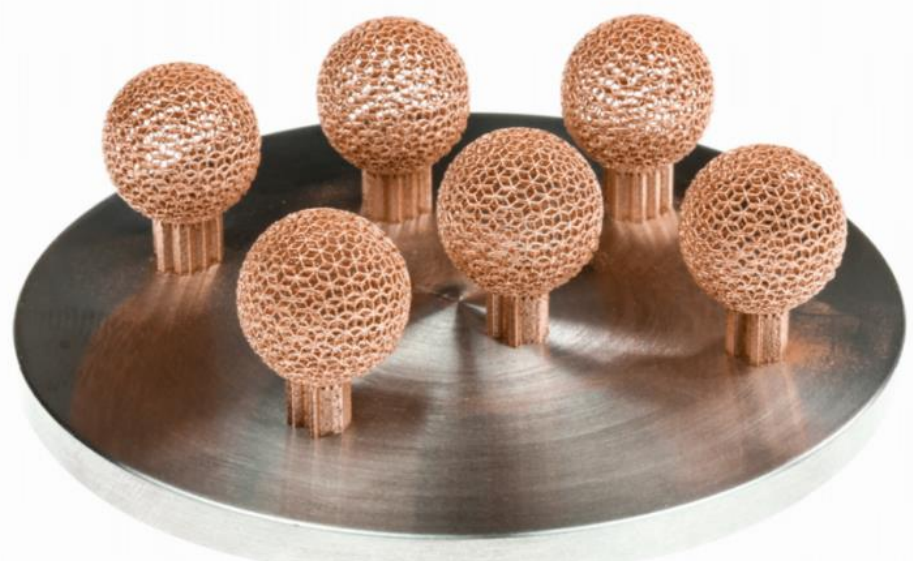

Fonte: cooksongold-emanufacturing.com (2018) 
A impressão em metal permite obter peças impossíveis de conseguir pelo método tradicional de fundição, como a produção de elos já unidos em forma de corrente ou peças ocas inteiras. Seria necessário produzir as partes separadamente e conectar através de solda com trabalho em banca de ourives ou laser, mesmo empregando o processo de impressão 3D em resina. Geometrias complexas também são uma das possibilidades permitidas, como é possível verificar nas figuras 5 e 6 .

Figura 6 - Projeto de estrutura articulada impressa em prata de aluno(a) da Birmingham City University

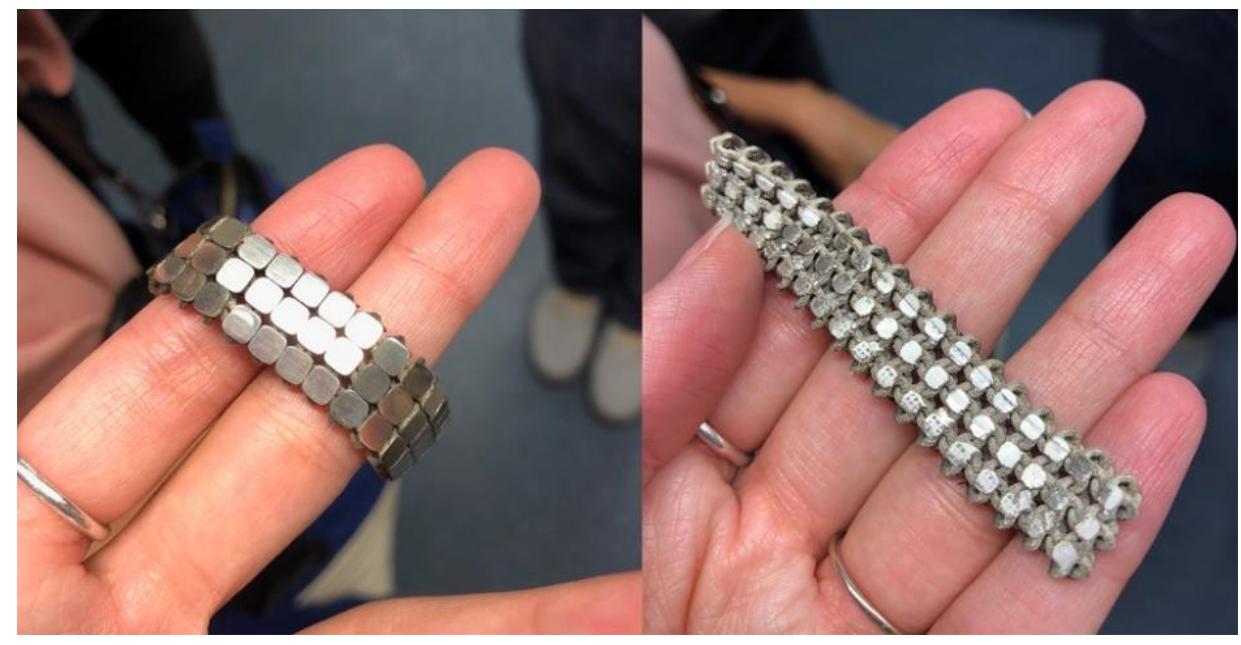

Fonte: a autora

A peça produzida necessita somente de acabamento superficial, caso seja necessário para adequar-se ao projeto e/ou permitir boa usabilidade.

\section{Conclusão}

A inserção das tecnologias de modelagem e fabricação digital no setor de adornos pessoais trouxe benefícios para a cadeia produtiva, permitindo o desenvolvimento de produtos com formas de maior complexidade e qualidade, e reduzindo o tempo de fabricação.

Mas toda tecnologia é aprimorada com o passar do tempo e novas formas de trabalho surgem. A modelagem paramétrica traz novas oportunidades para a indústria, permitindo inovação na forma com o desenvolvimento de geometrias complexas, reduzindo o retrabalho ao introduzir alterações em modelos de produtos existentes, viabilizando a engenharia reversa e capacitação de mão-de-obra.

Já a digitalização tridimensional pode ir além da aplicação no estudo de lapidação e aproveitamento de gemas. Essa tecnologia permite criar um modelo virtual a partir de um objeto real, o que é útil para a preservação de matrizes feitas à mão e outros dados inerentes ao processo produtivo, além de permitir a criação de um catálogo virtual desses produtos. Aliada à modelagem paramétrica, permite a alteração de modelos existentes e o desenvolvimento de novos com agilidade.

Mas tanto a modelagem paramétrica quanto a digitalização tridimensional são tecnologias para o desenvolvimento de modelos virtuais, que precisam ser transformados em modelos físicos. A 
impressão aditiva em metal permite a produção de formas complexas e produtos finalizados ou semifinalizados, sendo necessário somente acabamento superficial. Essa tecnologia também representa um avanço na construção de peças articuladas e ocas, pois permite que sejam produzidas de uma só vez, sem necessidade de união por soldagem.

Apesar de haver resistência por parte das empresas para a adoção de novas tecnologias de fabricação no setor de adornos corporais, fica claro que o investimento em modernização da linha produtiva é essencial para atuar num mercado competitivo global.

\section{Referências}

BATISTA, Claudia Regina. A modelagem 3D digital de joias e o processo de prototipagem rápida. In: GRAPHICA'13. XXI Simpósio Nacional de Geometria Descritiva e Desenho Técnico. X International Conference Graphics Engineering for Arts and Design. Florianópolis, Santa Catarina, 2013.

BENZ, Ida Elisabeth. Inovação no processo de design de joias através da modelagem 3D e da prototipagem rápida. 2009. 161 folhas. Dissertação (Mestrado em Design) - Departamento de Artes \& Design, PUC-Rio, Rio de Janeiro, 2009.

BRASIL. Portaria $n^{\circ} 43$, de 22 de janeiro de 2016. Determina que ficará proibida a comercialização de Bijuterias e Joias com concentrações de cádmio e chumbo iguais ou superiores, respectivamente, em peso, a $\mathbf{0 , 0 1 \%}$ e $\mathbf{0 , 0 3 \%}$ do metal presente no produto individualmente considerado. INMETRO, 2016.

ESPINOZA, Cristina. Inovação na criação de joias: uma reflexão sobre design, cultura e tecnologia. 2013. 142 folhas. Dissertação (Mestrado em Design de Equipamento) - Faculdade de Belas-Artes, Universidade de Lisboa, Lisboa, 2013.

FRANCO, Elizabeth. Decifrando sinais da Joalheria Contemporânea. In: Simpósio Nacional de Ourivesaria, Joalheria e Design, 1, 2017, Belo Horizonte. Anais... Belo Horizonte: recurso eletrônico, p. 276, 2017.

GIULIO, Gabriela Di. Polo de Joias e Bijuterias Cresce com Informalidade e Pouca Inovação. Revista Inovação Uniemp, v. 3, n.2, p. 42-45, Campinas, mar./abr., 2007.

GULATI, Vishal; TANDON, Puneet; SINGH, Hari. A Jewelry Modeler for Carved Bangles. In: International Journal of Computer Applications, v. 5, n. 2, p. 25-27, ago. 2010.

HILKENE, C. Process Advances Bring Metal 3D Printing into the Mainstream. ECN: Electronic Component News. 61, 9, 12-14, Oct. 2017.

IBGE - Instituto Brasileiro de Geografia e Estatística. Disponível em <http://www.ibge.gov.br/>. Acesso em 17/09/2017.

MAPEAMENTO DA INDÚSTRIA CRIATIVA NO BRASIL: JOIAS, BIJUTERIAS E AFINS. Rio de Janeiro: Sistema FIRJAN, 2014.

MINEIRO, Érico Franco. Experimentação em Design como Estratégia no Cenário da Autoprodução. 2016. 201 folhas. Tese (Doutorado em Design) - Departamento de Artes \& Design, PUC-Rio, Rio de 
Janeiro, 2016.

NETO, Rui; ALVES, Jorge Lino; DUARTE, Teresa; GOMES, Frederico. Utilização da Impressão 3D na Produção de Peças Metálicas. 2015. 5 folhas. Instituto de Ciência e Inovação em Engenharia Mecânica e Engenharia Industrial, Faculdade de Engenharia, Universidade do Porto, Porto, 2015.

SOUZA, Eduardo Presser. Contribuição ao Estudo da Aplicação da Digitalização Tridimensional para - Design e a Lapidação de Gemas. 2010. 121 folhas. Dissertação (Mestrado em Design e Tecnologia) Universidade Federal do Rio Grande do Sul, Porto Alegre, 2010.

VIARO, Felipe Schneider; PINHEIRO, Rogélio; SILVA, Régio Pierre da; TEIXEIRA, Fábio Gonçalves; BRUSCATO, Underléa Miotto. Projeto de Produto Utilizando Processos de Modelagem Paramétrica, Prototipagem e Fabricação Digital. In: Congresso Brasileiro de Pesquisa e Desenvolvimento em Design, 11., 2014, Gramado. Anais... Gramado: Blucher Design Proceedings, n.4, vol. 1, set./out., 2014.

VILLAMIZAR, Luis Alberto Laguado; RODRÍGUEZ, Laura Elisa Olivella. Diseño y manufactura de uma colección de accesorios de joyería generada a partir de geometrías paramétricas: análisis formal de tres especies em vía de extinción. Revista Iconofacto, v. 11, n. 16, p. 213-227, Medellín, jan./jun. 2015.

VOLTOLINI, Giovani. Design paramétrico e modelagem algorítmica: Os efeitos de seus conceitos e técnicas em acadêmicos de arquitetura. 2016. 205 folhas. Dissertação (Mestrado em Arquitetura e Urbanismo) - Centro Tecnológico, Universidade de Santa Catarina, Santa Catarina, 2016. 